\title{
Can economic indicators predict infectious disease spread? A cross-country panel analysis of $13 \mathrm{EU}$ countries
}

Paul R Hunter* ${ }^{1}$, Felipe J Colón-González ${ }^{2}$, Julii Brainard ${ }^{1}$, Batsirai Majuru ${ }^{1}$, Debora Pedrazzoli ${ }^{3}$, Ibrahim Abubakar ${ }^{4}$, Girmaye Dinsa ${ }^{5}$, Marc Suhrcke ${ }^{6}$, David Stuckler ${ }^{7}$, Tek-Ang Lim$^{8}$ and Jan C. Semenza ${ }^{9}$

${ }^{1}$ Norwich Medical School, University of East Anglia, UK

${ }^{2}$ School of Environmental Sciences, University of East Anglia, UK

${ }^{3}$ Centre for Mathematical Modelling of Infectious Diseases, London School of Hygiene and Tropical Medicine, London, UK

${ }^{4}$ Institute for Global Health, University College London, UK

${ }^{5}$ Harvard T.H. Chan School of Public Health, MA USA

${ }^{6}$ Centre for Health Economics, University of York, UK

${ }^{7}$ Dondena Research Centre, University of Bocconi, Milan, Italy

${ }^{8}$ Science and International Office, French Public Health Agency, France

${ }^{9}$ European Centre for Disease Prevention and Control (ECDC), Stockholm, Sweden

* Corresponding Author

Abstract

Background: It is unclear how economic factors impact on the epidemiology of infectious disease. We evaluated the relationship between incidence of selected infectious diseases and economic factors including recession in 13 European countries between 1970 and 2010. 
Methods: Data were obtained from national communicable disease surveillance centres.

Negative binomial forms of Generalised Additive and Generalised Linear Models (GAM and GLM) were tested to see which best reflected transmission dynamics of: diphtheria, pertussis, 
measles, meningococcal disease, hepatitis B, gonorrhoea, syphilis, hepatitis A and salmonella. Economic indicators were gross domestic product per capita (GDPpc), unemployment rates, and recession.

Results: GAM models produced the best goodness of fit results. The relationship between GDPpc and disease incidence was often nonlinear. Strength and directions of association between population age, tertiary education levels, GDPpc and unemployment were disease dependent. Under dispersion for almost all diseases validated the assumption of a negative binomial relationship. Recession was not independently linked to disease incidence. Conclusions: Social and economic factors can be correlated with many infections . However, the trend is not always in the same direction and these associations are often non-linear. Recession as an indicator of increased disease risk may be better replaced by GDPpc or unemployment measures.

Keywords: GDP, generalised additive models, Europe, infectious diseases

\section{Introduction}

Lessons from historical literature and research suggest that the impacts of an economic downturn can be far reaching. ${ }^{1}$ These include: shifts in trends in health risk, such as immunisation levels and utilisation of health services; differential impact on vulnerable population groups; and shifts in demand for health services from private sector to public sector. ${ }^{2}$

In high-income countries such as most of Europe, successes in infectious disease prevention and control have been high. However, $9 \%$ of the disease burden in Europe in Disability Adjusted Life Years (DALYs) is still attributable to infectious diseases. ${ }^{3}$ The realworld impacts from financial crisis on infectious disease prevention and control in modern European conditions are unclear. ${ }^{4,5}$ It is clear that austerity budgets often lead to reduced service provision. For instance, diminished screening, treatment and case management services were 
documented over the period 2008-2009 for American services in sexual health. ${ }^{6}$ A 2009-2010 survey among European infectious disease experts and policy-makers also found considerable concern about budget cuts specifically in relation to infectious disease prevention services and in particular those programmes targeted at vulnerable subgroups such as drug abusers and sex workers. ${ }^{7}$

There is a significant body of literature evaluating the relationships between health outcomes and economic status. Concerns that infection control measures would specifically be reduced because of austerity budgets have been voiced. ${ }^{4}$

However, research on how the recent economic recession influenced epidemiological patterns is limited. Generally, incidence of communicable diseases in high income countries seems to have fallen in the last decade, ${ }^{5,8}$ but some increases in observed communicable diseases were observed following the 2007/08 financial crisis, notably for influenza, West Nile virus, HIV and indigenous malaria in Greece. ${ }^{9,10}$ However, most studies to review incidence of poor health linked to the financial crisis have tended to dwell on chronic diseases (including impacts on mental health) and overall mortality rates, rather than communicable diseases. ${ }^{5,8,11}$ Lack of research on changes in infectious diseases is partly due the paucity of observed and comparable data across countries and regions and differences in models and indicators used. ${ }^{5,12}$

The analysis in this study seeks to improve understanding of the relationship between macroeconomic factors and infectious disease incidence in the European Union (EU) through a quantitative assessment across $13 \mathrm{EU}$ countries. Such an understanding is valuable, as it would provide guidance on the future impact of macroeconomic downturns for the spread of infectious diseases. The ensuing appropriate and effective policy responses and strategies would not only mitigate potential negative health impact, but also maximise the efficiency of health systems 
during periods of macroeconomic downturn.

\section{Methods}

\section{Epidemiological data}

We approached all national infectious diseases surveillance centres within the European Union for access to their infectious disease surveillance data from the years 1970 onwards. Some data were already available in the public domain, and some were generated specifically for the researchers. In choosing which diseases to study we wanted to ensure that we had representative selections of vaccine preventable diseases, infections spread by sexual contact and also foodborne and person-to-person spread enteric infections. In addition, we were only interested in infections that were likely to be included in most national disease surveillance systems over most of the study period. We excluded diseases based on these criteria:

- Diseases where widespread use of effective diagnostic methods was only recent or was slow to be adopted across Europe (such as Hepatitis C, Chlamydia, Cryptosporidiosis and Campylobacter).

- Notifiable diseases where the recent incidence in most countries was very low/non-existent (such as cholera).

- Infectious diseases where diagnosis is most often delayed (such as HIV).

- Diseases with substantial year on year variation because of pathogen specific factors (i.e. influenza).

- Tuberculosis because of long latency. 


\section{Economic data}

This led to four vaccine preventable diseases (diphtheria, measles, pertussis and meningococcal infection), three sexually transmitted or blood-borne disease (gonorrhoea, syphilis and hepatitis B) and two food borne diseases (salmonella and hepatitis A). We acquired data on unemployment, GDP per capita (measured in USD), tertiary education enrolment and demographic characteristics from the World Bank's World Development Indicators. ${ }^{13}$ Data were obtained for Finland, Germany, Hungary, Ireland, Italy, the Netherlands, Norway, Poland, Portugal, Spain, Romania, Sweden and the United Kingdom.

\section{Analytical approach}

Our outcome variable was the disease total annual count of disease reports per country. Our principal macroeconomic predictor variables were unemployment and Gross Domestic Product per capita (GDPpc). We also incorporated a Boolean variable representing recession years determined by whether or not GDP had declined over the previous year as a proxy for macroeconomic downturn. Hence, a "recession" in the context of this study was defined as negative growth in GDPpc from one year to the next. We also adjusted the models for the proportion of people who were enrolled in tertiary education (gross enrolment ratio from World Bank data).

We initially explored the effects of the most recent recession period (i.e. 2008-2010) upon the different disease reports. For comparative purposes, we also explored the effects of other recession periods (1970-2010) using an Organisation of Economic Development (OECD) Composite Leading Indicators data set. ${ }^{14}$ Boolean variables were created to indicate recession 
periods on both the 2008-2010 and the 1970-2010 data sets.

\section{Statistical model}

The expected number of cases for each disease $E(Y i t)$ for country $i=1, \ldots, I$ at year $t=1, \ldots, T$ was modelled using a generalized additive model (GAM) approach to account for potential nonlinear associations between variables. GAMs are semi-parametric extensions of the widely used generalized linear model where the linear predictor is replaced by the sum of smooth functions of the covariates. ${ }^{15}$ The optimal degree of non-linearity between the outcome and the predictors is estimated using Generalized Cross-Validation. ${ }^{16}$ To account for possible overdispersion in the data, we fitted Negative Binomial models. The general algebraical definition of the models is given by:

$$
\begin{gathered}
\log \left(\mu_{i t}\right)=\eta_{i t} \\
\eta_{i t}=\alpha+\log \left(\xi_{i t}\right)+\log \left(Y_{i t}-1\right)+\mathrm{t}^{\prime}+\sum_{1}^{P} f(x i t, 1)+\sum_{1}^{Q} \beta(z i t)+d_{i}
\end{gathered}
$$

where $\eta_{i t}$ is a natural logarithmic link function of the expectation $\mathrm{E}\left(Y_{i t} \equiv \mu_{i t}\right)$, with $Y_{i t}$ as the time series of annual disease reports. The term $\alpha$ corresponds to the intercept; $\log \left(\xi_{i t}\right)$ denotes the natural logarithm of the population at risk for country $i$ and year $t$ included as an offset to adjust the epidemiological data by population. $\log \left(Y_{i t}-1\right)$, is the natural logarithm of the outcome disease counts lagged one year to account for potential auto-correlation in the data. ${ }^{17}$ Here, $t$ ' is an index variable of year to control for possible long-term trends. The term $\mathrm{f}\left(x_{i}, 1\right)$ corresponds to smoothed relationships between the socioeconomic predictors lagged zero to three years and disease incidence defined by cubic regression splines. Lagged socioeconomic variables were 
computed using a four-year moving average for the year variable to account for the lagged effects of the socioeconomic predictors on disease incidence. The demographic predictors $z_{i t}$ with regression coefficients $\beta$ enter the model linearly. Country-specific fixed effects $\left(d_{i}\right)$ were included to account for unknown or unobserved variables in the models. ${ }^{18}$

\section{Model selection}

Some arguments were constant to all models. First, the logarithm of the population was incorporated as an offset to estimate relations on the crude incidence rate rather than on the total number of cases. Second, the logarithm of the outcome variable lagged one year was included in all models because epidemiological observations near in time are likely to be more similar than those distant in time. ${ }^{17}$ Third, an index variable for the year of the observations was incorporated to control for potential long-term trends that may be due to factors other than socioeconomic development. ${ }^{19}$ Finally, we incorporated country-specific fixed effects to account for unknown or unobserved variables in the model such as diagnostic performance variability, and interventions. ${ }^{18}$ All models were fitted using the "mgcv" package for R. ${ }^{20}$

A series of models were then fitted using all socioeconomic predictors (GDP per capita and unemployment and tertiary education) lagged 0:3 years, and all demographic predictors (population 15-65 years, and population over 65 years) in isolation, as well as in all their possible combinations. Thus, we successively fitted all possible models containing one socioeconomic or demographic predictor at a time, then two predictors at a time, and so on, until all predictors were included altogether in a single model. We measured the goodness of fit of each model using the Akaike information criterion (AIC). ${ }^{21}$ The model with the lowest AIC value was selected.

\section{Comparative analyses}


To ensure the robustness of our estimates, we compared the results of our Negative Binomial GAM against those obtained using a Negative Binomial generalised linear model (GLM). The model specification of these models was as in the GAM models except for the smooth predictors $f(x i t, 1)$ that entered the model linearly instead.

\section{Results}

Overall, disease incidences had a downward trend from 1970 to 2010 . Table 1 presents the summary statistics for each disease and economic variable. The panel data set contained countryspecific observations for a 41 year period for a total of 513 country-year data points. The average sample per disease amounts to 296 country-year observations due to missing data. 
Table 1: Summary statistics across all countries and years

\begin{tabular}{|l|l|l|l|l|l|l|}
\hline Outcome & Mean & Median & SD & $\begin{array}{l}\mathbf{2 5}^{\text {th }} \\
\text { percentile }\end{array}$ & $\begin{array}{l}\mathbf{7 5}^{\text {th }} \\
\text { percentile }\end{array}$ & $\mathbf{N}$ \\
\hline Diphtheria & 19.3 & 0.0 & 73.3 & 0.0 & 3.0 & 331 \\
\hline Gonorrhoea & 6012.0 & 981.0 & 9993.7 & 284.0 & 8275.0 & 305 \\
\hline Hepatitis A & 6956.0 & 489.0 & 15576.5 & 166.0 & 2416.0 & 261 \\
\hline Hepatitis B & 2160.5 & 387.5 & 3709.3 & 166.2 & 2084.5 & 256 \\
\hline Measles & 18185.0 & 415.0 & 41272.5 & 28.0 & 9024.0 & 363 \\
\hline Meningococcal & 498.7 & 233.0 & 827.7 & 96.5 & 500.5 & 303 \\
\hline Pertussis & 3482.0 & 587.0 & 7447.4 & 107.0 & 3092.0 & 342 \\
\hline Salmonella & 17393.0 & 6653.0 & 27037.5 & 2304.0 & 23097.0 & 239 \\
\hline Syphilis & 1566.0 & 545.0 & 2402.9 & 190.0 & 1822.0 & 263 \\
\hline Predictor & Mean & Median & SD & $\begin{array}{l}\mathbf{2 5} \\
\text { percentile }\end{array}$ & $\begin{array}{l}\mathbf{7 5} \\
\text { percentile }\end{array}$ & N \\
\hline GDPpc & 21929.0 & 21077.0 & 8924.7 & 15340.0 & 27934.0 & 438 \\
\hline Unemployment & 8.5 & 7.7 & 4.5 & 5.3 & 10.5 & 310 \\
\hline Tertiary & 36.8 & 31.5 & 21.1 & 18.9 & 54.2 & 453 \\
\hline
\end{tabular}

Notes: Data from sources described in text. Units are, Diseases: counts per country. GDPpc: USD. Unemployment: \%. Tertiary education: gross enrolment ratio.

We tried 31 different model specifications for each disease in the data set. The model specification with the lowest AIC estimate was selected. The selection based on the lowest AIC lead to different model parameters being used for each disease. Table 2 presents the results for the final models selected for each disease. The values in bold font indicate that the estimate was significant at the 0.05 level. Note that a great deal of the deviance is explained by the selected models (explained deviance range: 85\%-99\%). With the exception of the model for Diphtheria that suggests that data were under-dispersed (dispersion $=0.478)$, the dispersion statistic of all models was close to one suggesting that the Negative Binomial specification of the model was adequate to account for potential over-dispersion in the data. 
The Boolean variable used here to specify the $2008-2010$ recession period was not significant for any of the diseases after having accounted for the effects of autocorrelation, long-term trends, and the demographic and macroeconomic predictors in the model. Such observation suggests that the 2008-2010 recession did not play a significant role on the occurrence of the diseases under scope. Similar results were obtained when accounted for all recession years (i.e. 1970, 1971, 1973, 1975, 1980-1982, 1986, 1990-1993, 1995, 1996, 1998, 2000-2003, and 20082010) based on the OECD data. 
Table 2: GAM estimated relationships between disease incidence and each predictor incorporated in the final models

\begin{tabular}{|c|c|c|c|c|c|c|c|c|c|}
\hline Term & Diptheria & Gonorrhoea & $\begin{array}{l}\text { Hepatitis } \\
\text { A }\end{array}$ & HepatitisB & Measles & $\begin{array}{l}\text { Men'l } \\
\text { Disease }\end{array}$ & Pertussis & Salmonella & Syphillis \\
\hline $\log ($ Yit-1) & -0.027 & 0.748 & 0.624 & 0.697 & 0.282 & 0.742 & 0.575 & 0.512 & 0.453 \\
\hline Year & 0.526 & -0.030 & 0.045 & -0.001 & 0.024 & -0.008 & 0.089 & -0.001 & 0.010 \\
\hline Recession & -0.656 & 0.084 & 0.083 & -0.045 & 0.583 & -0.063 & -0.194 & -0.030 & 0.019 \\
\hline Tertiary & - & 0.008 & $>0.001$ & 0.002 & -0.089 & 0.001 & 0.006 & -0.012 & 0.027 \\
\hline $\begin{array}{l}\text { Population } \\
\text { 15-65 yrs }\end{array}$ & -0.554 & -0.092 & -0.069 & 0.049 & -0.202 & 0.052 & -0.261 & -0.053 & -0.055 \\
\hline $\begin{array}{l}\text { Population } \\
\text { Age 65+ }\end{array}$ & -2.287 & -0.096 & -0.434 & -0.175 & -0.315 & - & -0.469 & - & - \\
\hline $\begin{array}{l}\text { Country } \\
\text { fixed } \\
\text { effects }\end{array}$ & Included & Included & Included & Included & Included & Included & Included & Included & Included \\
\hline \multicolumn{10}{|c|}{ Smoothers (edf) } \\
\hline GDPpc & 2.932 & 1.001 & 3.733 & 7.210 & 6.794 & 1.001 & 4.317 & 5.836 & 7.174 \\
\hline $\begin{array}{l}\text { Unemploy- } \\
\text { ment }\end{array}$ & 1.000 & 1.000 & 2.436 & 2.491 & 1.006 & 1.000 & 1.002 & 5.369 & 4.615 \\
\hline \multicolumn{10}{|c|}{ Model statistics } \\
\hline Dispersion & 0.478 & 1.099 & 1.506 & 1.296 & 1.412 & 1.202 & 1.437 & 1.098 & 1.229 \\
\hline $\begin{array}{l}\text { Deviance } \\
\text { explained }\end{array}$ & 0.958 & 0.975 & 0.940 & 0.974 & 0.846 & 0.967 & 0.901 & 0.990 & 0.975 \\
\hline
\end{tabular}

Values in bold font were significant at the 0.05 level. edf=estimated degrees of freedom. The dashes indicate that the parameter was not included in the model.

A positive relationship was observed between the increasing access to tertiary education and the occurrence of Gonorrhoea and Syphilis suggesting that as access to tertiary education increases, so does the incidence of these two sexually transmitted diseases. Conversely, a negative relationship was observed between the increasing access to tertiary education and the occurrence of Measles and Salmonella suggesting a possible protective effect of education against these diseases.

The proportion of the population with 65 years of age or more showed a negative and 
significant effect on disease occurrence in all models where it was included except for Hepatitis B (Table 2). Similarly, we estimate a negative relationship between the proportion of the population between 15 and 65 years of age and the occurrence of Diphtheria, Gonorrhoea and Pertussis. The estimated degrees of freedom (edf) of the smoothed macroeconomic predictors suggest that the relationship between GDPpc and disease occurrence is highly nonlinear (edf $>1$ ) for all diseases except for Gonorrhoea and Meningococcal infection where we estimate a loglinear relationship $(\mathrm{edf} \approx 1)$. The relationship between disease occurrence and unemployment was also highly nonlinear for Hepatitis A, Hepatitis B, Salmonella and Syphilis, and approximately log-linear for all the other diseases.

Figure 1 depicts the functional form of the estimated effects of GDPpc and unemployment on disease occurrence. The $\mathrm{X}$ axis indicates the values of the macroeconomic predictors, and the $\mathrm{Y}$ axis the estimated response of the disease outcome variable in a logarithmic scale. Diphtheria data are described in text but not shown in Figs. 1-2 due to a greater than two factor of two difference in average incidence compared to all the other diseases, as indicated by summary statistics in Table 1.

It is important to note that the direction of the association varies between the different diseases. Overall, we estimate a protective effect (decline in disease) with rising GDPpc for Diphtheria, Hepatitis A, Hepatitis B, Meningococcal infection and Syphilis. Conversely, a positive effect was estimated for Gonorrhoea and Measles. GDPpc showed a quadratic-like relationship with Salmonella with a gradual rise in log-incidence up to about USD 25,000 after which the rate of increase in incidence levels off and then decays at about USD 35,000. The relationship between GDPpc and Syphilis is interesting as there is a marked decrease in logincidence for values below USD 28,000 after which the effect flattens. The estimated effect of 
unemployment was positive for Measles, Pertussis, and Salmonella and negative or not significant for the other diseases. Similar results were estimated for the two macroeconomic predictors when accounting for the effects of all recession periods in the model.
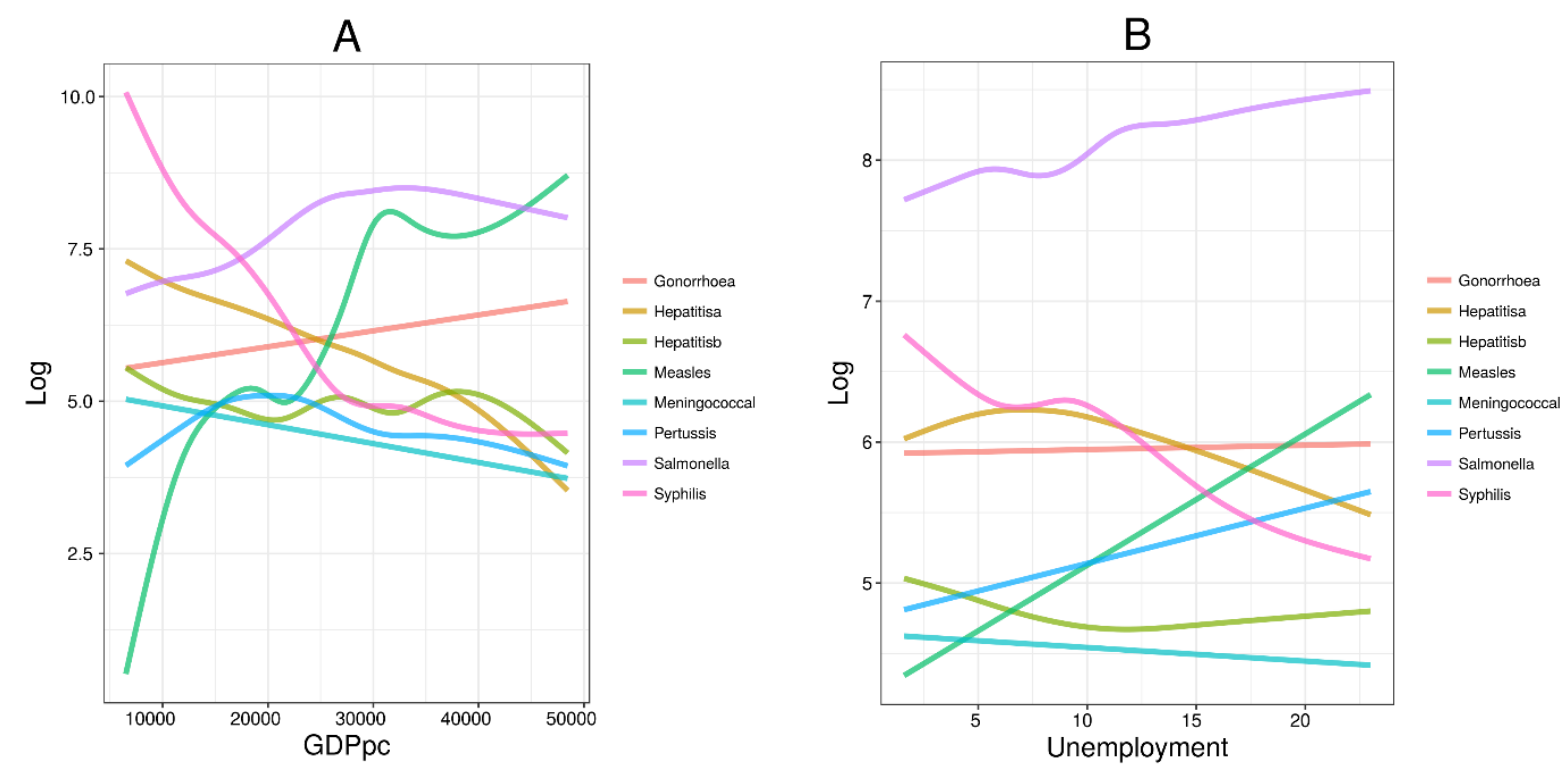

Figure 1: GAM-estimated smooth relationships between disease occurrence and (A) GDP per capita, and (B) unemployment. Diptheria not shown on from the figures due to scale incompatibility. 
When we compared the results obtained with our Negative Binomial GAM against those from the Negative Binomial GLM, we observed an increase in the dispersion parameter and a decrease in the explained deviance (Table 3). The increase in the dispersion parameter suggests that some of the covariates in the Negative Binomial GAM may indeed have a nonlinear effect. Replacing the smoothed macroeconomic predictors with linear predictors resulted in relationships that were mainly not significant at the 0.05 level both for GDPpc and unemployment. 
Table 3: GLM estimated coefficients and model statistics

\begin{tabular}{|c|c|c|c|c|c|c|c|c|c|}
\hline Term & Diptheria & Gonorrhoea & $\begin{array}{l}\text { Hepatitis } \\
\text { A }\end{array}$ & HepatitisB & Measles & $\begin{array}{l}\text { Men'l } \\
\text { Disease }\end{array}$ & Pertussis & Salmonella & Syphillis \\
\hline $\log ($ Yit-1) & 0.045 & 0.749 & 0.674 & 0.785 & 0.334 & 0.743 & 0.613 & 0.771 & 0.690 \\
\hline Year & 0.608 & -0.030 & 0.028 & -0.031 & 0.056 & -0.009 & 0.066 & 0.011 & -0.018 \\
\hline Recession & -1.122 & 0.084 & 0.108 & -0.076 & 0.449 & -0.064 & -0.084 & -0.068 & 0.046 \\
\hline $\begin{array}{l}\text { Tertiary- } \\
\text { education }\end{array}$ & - & 0.008 & -0.001 & -0.004 & -0.056 & 0.001 & 0.016 & -0.006 & 0.006 \\
\hline $\begin{array}{l}\text { Population } 15- \\
65 \text { yrs }\end{array}$ & -0.520 & -0.092 & -0.033 & 0.020 & -0.082 & 0.052 & -0.150 & -0.001 & -0.102 \\
\hline $\begin{array}{l}\text { Population age } \\
65+\end{array}$ & -2.089 & -0.096 & -0.310 & -0.023 & -0.311 & - & -0.412 & - & - \\
\hline $\begin{array}{l}\text { Country fixed } \\
\text { effects }\end{array}$ & Included & Included & Included & Included & Included & Included & Included & Included & Included \\
\hline GDPpc & -0.001 & $<0.001$ & $<0.001$ & $<0.001$ & $<0.001$ & $<0.001$ & $<0.001$ & $<0.001$ & $<0.001$ \\
\hline Unemployment & -0.184 & 0.003 & -0.036 & -0.017 & -0.003 & -0.010 & 0.045 & 0.009 & -0.021 \\
\hline \multicolumn{10}{|c|}{ Model statistics } \\
\hline Dispersion & 0.559 & 1.116 & 1.590 & 1.450 & 1.831 & 1.205 & 1.486 & 1.177 & 1.305 \\
\hline $\begin{array}{l}\text { Deviance- } \\
\text { explained }\end{array}$ & 0.931 & 0.970 & 0.900 & 0.939 & 0.778 & 0.956 & 0.880 & 0.969 & 0.948 \\
\hline
\end{tabular}

Note: Values in bold font were significant at the 0.05 level. edf $=$ estimated degrees of freedom.

The direction of the GLM-estimated relationships between disease incidence, GDPpc and unemployment was similar for most GAMs and GLM models (Figure 2). This was not the case, however, for the relationships between GDPpc, Hepatitis B, Salmonella and Syphilis. 

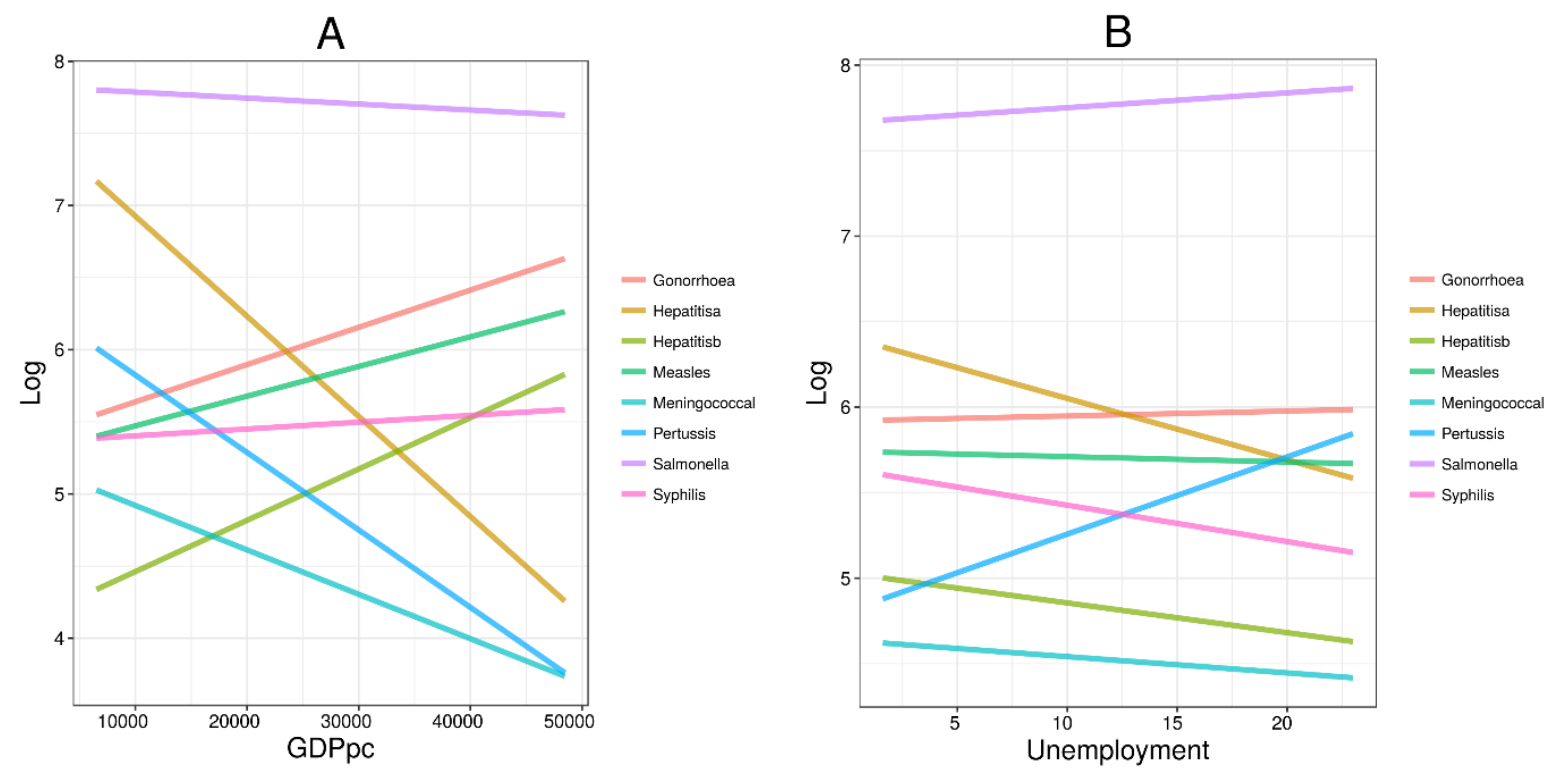

Figure 2: GAM-estimated smooth relationships between disease occurrence and (A) GDP per capita, and (B) unemployment. Diptheria not shown on from the figures due to scale incompatibility. 


\section{Discussion}

For this study we brought together one of the most comprehensive annualised datasets on infectious disease reporting across different European Union member states to date. We then used this dataset to model the impact of standard macroeconomic variables on disease incidence. We demonstrate that the relationships between these economic variables and disease incidence are highly non-linear.

If, as we suspect, non-linearity between economic variables and outcome variables is common and consistent, then using linear models to predict changes in incidence of public health problems $^{22-25}$ may be inappropriate, as it will likely under-estimate the impact of macroeconomic drivers on disease incidence.

Our analysis found significant but non-linear relationships between the incidence of many of the infectious diseases and economic variables. We found that generally, rising per capita GDP had a protective effects against diphtheria, hepatitis A and B, meningcoccal disease, gonnorrhea and measles. In contrast, rising unemployment (an indicator of economic downturn) also had a protective effect against most diseases, except gonnorrhoea, measles pertusussis and salmonella. While it is interesting to speculate on the mechanisms underlying the associations between disease incidence and economic variables identified in this study, it is important to remark that any suggestions for such mechanisms do not themselves come out of the data and cannot be confirmed or refuted from the available data. It should also be remembered that the non-linear relationship between many of the infectious diseases and economic variables means that a change in an economic variable, either within the same country over time or between countries will depend on the starting value.

Economic theory suggests that unemployment and GDP should have opposite 
relationships with the same indicators (because unemployment falls as GDP rises, see Okun's Law, $\left.{ }^{26}\right)$. However, collinearity means that it is reasonable to view GDP as the primary predictor in these models; and thus where the relationship between disease incidence and unemployment runs counter to intuition, this may reflect collinearity with GDP in the same model, rather than an underlying distinct economic relationship. Therefore the below discussion will focus on possible explanations for the apparent relationship between GDP (only) and disease incidence.

An increase in Gonorrhoea with rising GDP may reflect increasingly relaxed social attitudes about sexual activity, accompanied by widespread subclinical and hence untreated infection. This suggestion may seem to contradict the fall of cases of Syphilis (fall with rising GDP). However, the clinical course of Syphilis is very different from Gonnorrhoea. Syphilis is noted for multiple phases of symptoms, sometimes including long dormant periods followed by quite severe health problems. This contrasts with Gonnorrhea which may never cause symptoms at any stage of infection.

The fluctuating relationships (rises and falls) of some diseases (Hepatitis B, Meningoccocal) with GDP probably reflects multiple unconsidered factors, such as different immunisation programmes in different countries for these diseases. Hepatitis A, whose main risk factor is sanitation and hygiene practices, ${ }^{27}$ shows a marked decline with increasing GDPpc. As the disease has been more common in poorer regions such as Eastern and Central Europe ${ }^{28}$ the improvement in sanitation associated with increased GDP in these regions could likely be a factor in the reduction of the disease. There was a marked decline in hepatitis A incidence in Hungary, Poland and Romania (data not shown). While the incidence of vaccine preventable infections generally shows a negative association with increasing GDPpc, measles is a striking exception. Increasingly large outbreaks of the disease continue to occur in Europe, as a result 
sub-optimal vaccination uptake. ${ }^{29-32}$

We have been transparent about the limitations in the work presented here. Because our dataset is based on annual data, our definition of recession is limited to year on year decline in GDP, which differs somewhat from the more commonly used definition of two consecutive quarters of declining GDP. ${ }^{33}$ Thus our reliance on annual changes in GDP prevents us from detecting within-year relationships in the variables. Also, although our study presents what is perhaps the most comprehensive dataset of notifiable infectious diseases across a number of European countries, this dataset is not complete for all countries. This could have masked the full extent of relationships between macroeconomic factors and infectious diseases. Overall differences in the sensitivity of surveillance between countries are accounted for in the panel structure of our analyses. However, the analyses cannot account for potential temporal changes in sensitivity of surveillance within countries. Our modelling strategy was narrow, we did not consider other modelling approaches, such as segmented regression which can also overcome some of the shortcomings associated with using simple linear regression to describe the possible relationship between disease incidence and economic indicators. ${ }^{34-36}$

One issue that deserves further comment is the inclusion of lagged log incidence in order to control for autocorrelation in disease incidence within country. It has been pointed out that the use of lagged variables in Generalised Least Squares or Ordinary Least Squares can "squash" the apparent effect of other predictor variables. ${ }^{37}$ Achen showed that this could be artefactual and due to a combination of high serial correlation and heavy trending in the exogenous variables. ${ }^{37}$ However, as pointed out more recently, the use of lagged dependent variables is often appropriate for dynamic models. ${ }^{38}$ Given that most models of infectious disease epidemiology are highly dynamic the inclusion of a lagged dependent variable is appropriate. Furthermore, all 
of the evidence against the use of lagged variables is based on linear regression models and may not apply to the GAM used here.

\section{Conclusions}

The prevailing macroeconomic climate and its impact on disease outcomes remains a significant concern. Evidence on both the nature and the likely outcomes of these relationships is key to decision-making. Here we have reported on the relationships between macroeconomic factors and infectious disease outcome across 13 European countries and over a period of 40 years (1970-2010). Most notably, compared to linear models, our application of Generalised Additive Models proved to give a valid and best fit. A key finding from this study are highly non-linear relationships between macroeconomic indicators and infectious disease incidence. We found limited evidence of the effect of recession on infectious disease independent of any effect of GDPpc, but other macroeconomic factors may be important drivers of the disease trends observed.

\section{Funding}

This study was supported by the European Centre for Disease Control and Prevention. Paul Hunter, Julii Brainard and Felipe J Colón-González are affiliated to the National Institute for Health Research (NIHR) Health Protection Research Unit in Emergency Preparedness and Response at Kings College London in partnership with Public Health England (PHE) in collaboration with University of East Anglia, University of Oxford and the Institute of Food Research. The views expressed are those of the authors and not necessarily those of the NHS, the NIHR, the Department of Health, or PHE.

\section{References}

1 Suhrcke M, Stuckler D, Suk JE, Desai M, Senek M, McKee M, et al. The impact of economic crises on communicable disease transmission and control: a systematic review of the evidence. PloS One 2011; 6(6): e20724. 
2 Phua K-L. Can we learn from history? Policy responses and strategies to meet health care needs in times of severe economic crisis. Open Public Health J 2011; 4: 1-5.

3 Mladovsky P, Allin S, Masseria C, Hernández-Quevedo C, McDaid D, Mossialos E. Health in the European Union: Trends and analysis. European Observatory on Health Systems and Policies, 2009.

4 Semenza JC, Tsolova S, Lim TA. Economic crisis and infectious disease control: a public health predicament. Eur J Public Health 2012; 22(1): 5-6.

5 Karanikolos M, Mladovsky P, Cylus J, Thomson S, Basu S, Stuckler D, et al. Financial crisis, austerity, and health in Europe. Lancet 2013; 381: 1323-1331.

6 National Coalition of STD Directors. STD programs facing severe cutbacks, affecting public health infrastructure: Economic crisis impacting health department capacity to address rising STD rates. 2009.

http://www.ncsddc.org/sites/default/files/docs/releases/ncsd_member_survey_and_surveillance_ press_release_11.pdf (accessed 20 January 2012).

7 Rechel B, Suhrcke M, Tsolova S, Suk JE, Desai M, McKee M, et al. Economic crisis and communicable disease control in Europe: a scoping study among national experts. Health Policy 2011; 103(2-3): 168-75.

8 Baumbach A, Gulis G. Impact of financial crisis on selected health outcomes in Europe. European Journal of Public Health 2014; 24; 399-403.

9 Quaglio G, Karapiperis T, van Woensel L, Arnold E, McDaid D. Austerity and health in Europe. Health Policy 2013; 113; 13-19.

10 Bonovas S, Nikolopoulos G. High-burden epidemics in Greece in the era of economic crisis. Early signs of a public health tragedy. Journal Preventative Medicine and Hygiene 2012; 53; 169-171.

11 Toffolutti V, Suhrcke M. Assessing the short term health impact of the Great Recession in the European Union: A cross-country panel analysis. Preventative Medicine 2014; 64; 54-62. 
12 Or Z. Determinants of health outcomes in industrialised countries: A pooled, cross-country, time-series analysis. Organisation for Economic Co-operation and Development (OECD), 2000.

13 World Bank World Development Indicators Online (WDI) database.

http://data.worldbank.org/indicator, World Bank, 2010.

14 FRED (Federal Reserve Bank of St Louis) OECD based Recession Indicators for Euro Area from the Period following the Peak through the Trough (EUROREC)

https://fred.stlouisfed.org/series/EUROREC, FRED, 2016.

15 Hastie T, Tibshirani R. Generalized Additive Models. Stat Sci 1986; 1(3): 297-310.

16 Wood, SN. Generalized Additive Models: An Introduction with R. Chapman and Hall/CRC. 2006

17 Imai C, Armstrong B, Chalabi Z, Mangtani P, Hashizume M. Time series regression model for infectious disease and weather. Environ Res 2015; 142:319-327.

18 Colón-González FJ, Fezzi C, Lake IR, Hunter PR. The Effects of Weather and Climate Change on Dengue. PLoS Neglected Tropical Diseases. 2013;7(11):e2503.

19 Bhaskaran K, Gasparrini A, Hajat S, Smeeth L, Armstrong B. Time series regression studies in environmental epidemiology. International Journal of Epidemiology 2013;42(4):1187-1195.

20 R Development Core Team. R: A language and environment for statistical computing. Vienna, Austria: R Foundation for Statistical Computing; 2010.

21 Akaike H. Akaike's information criterion. In International Encyclopedia of Statistical Science, pp 25, Berlin Heidelberg: Springer; 2011.

22 Gerdtham UG, Ruhm CJ. Deaths rise in good economic times: Evidence from OECD. Economics and Human Biology 2006; 4; 298-316. 
23 Stuckler D, Meissner CM, King LP. Can a bank crisis break your heart? Globalization and Health 2008; 4.

24 Nikolopoulos GK, Fotiou A, Kanavou E, Richardson C, Detsis M, Pharris A, Suk JE, Semenza JC, Costa-Storti C, Paraskevis D and Sypsa V. National income inequality and declining GDP growth rates are associated with increases in HIV diagnoses among people who inject drugs in Europe: a panel data analysis. PLoS One 2015; 10; 4; e0122367.

25 Odone A, Signorelli C, Rodrigues LC. Tuberculosis and the economic crisis: an old threat for the new European agenda. Scandanavian Journal of Public Health 2014; 42; 834-835.

26 Lee J. The robustness of Okun's law: Evidence from OECD countries. Journal of macroeconomics 2000; 22(2): 331-356.

27 FitzSimons D, Hendrickx G, Vorsters A, Van Damme P. Hepatitis A and E: Update on prevention and epidemiology. Vaccine 2010; 28(3): 583-8.

28 Mogilevsky R. The impact of the global financial crisis on public health expenditures in the economies of the former Soviet Union: Center for Social and Economic Research, 2011.

29 Cottrell S, Roberts RJ. Measles outbreak in Europe. BMJ 2011; 342: d3724

30 Muscat M. Who Gets Measles in Europe? J Infect Dis 2011; 204(suppl 1): S353-S65.

31 Lim TA, Marinova L, Kojouharova M, Tsolova S, Semenza JC. Measles outbreak in Bulgaria: poor maternal educational attainment as a risk factor for medical complications. Eur $\mathrm{J}$ Public Health 2013; 23(4): 663-9.

32 European Centre for Disease Prevention and Control. Epidemiological update: Measles monitoring European outbreaks, 8 September 2017. Epidemiological Update 2017; https://ecdc.europa.eu/en/news-events/epidemiological-update-measles-monitoring-europeanoutbreaks-8-september-2017.

33 Lee K, Shields KK. Decision-making in hard times: What is a recession, why do 
we care and how do we know when we are in one? N Am Journal Econ Finance 2011; 22(1): 43-60.

34 Chang SS, Gunnell D, Sterne JAC, Lu TH, Cheng ATA. Was the economic crisis 1997-1998 responsible for rising suicide rates in East/Southeast Asia? A time-trend analysis for Japan, Hong Kong, South Korea, Taiwan, Singapore and Thailand. Social Science and Medicine 2009; 68(7): 1322-1331.

35 Regidor E, Barrio G, Bravo MJ, de la Fuente L. Has health in Spain been declining since the economic crisis? Journal of Epidemiology and Community Health

2014; 68: 280-282.

36 Funk S, Bogich TL, Jones KE, Kilpatrick AM, Daszak P. Quantifying Trends

in Disease Impact to Produce a Consistent and Reproducible Definition of an Emerging Infectious Disease. PloS one 2013; 8(8): e69951.

37 Achen $\mathrm{CH}$. Why lagged dependent variables can suppress the explanatory power of other independent variables. Presented at the Annual Meeting of the Political Methodology, Los Angeles. 2000 http://www.polmeth.wustl.edu/media/Paper/achen00.pdf

38 Keele L, Kelly N J. Dynamic models for dynamic theories: The ins and outs of lagged dependent variables. Political Analysis 2006; 14(2): 186-205. 